\title{
A Review of Automatic Patient Identification Options for Public Health Care Centers with Restricted Budgets
}

\author{
Rebeca I. García-Betances ${ }^{1}$, Mónica K. Huerta ${ }^{1}$ \\ ${ }^{1}$ Networks and Applied Telematics Group (GRETA), Simón Bolívar University, \\ Caracas, Venezuela.
}

\section{Abstract}

A comparative review is presented of available technologies suitable for automatic reading of patient identification bracelet tags. Existing technologies' backgrounds, characteristics, advantages and disadvantages, are described in relation to their possible use by public health care centers with budgetary limitations. A comparative assessment is presented of suitable automatic identification systems based on graphic codes, both one(1D) and two-dimensional (2D), printed on labels, as well as those based on radio frequency identification (RFID) tags. The analysis looks at the tradeoffs of these technologies to provide guidance to hospital administrator looking to deploy patient identification technology. The results suggest that affordable automatic patient identification systems can be easily and inexpensively implemented using $2 D$ code printed on low cost bracelet labels, which can then be read and automatically decoded by ordinary mobile smart phones. Because of mobile smart phones' present versatility and ubiquity, the implantation and operation of $2 D$ code, and especially Quick Response ${ }^{\circledR}$ (QR) Code, technology emerges as a very attractive alternative to automate the patients' identification processes in low-budget situations.

Keywords - Patient identification, Automatic identification, 2D Codes, RFID, ID tags, EHR.

\section{Introduction}

When patients are admitted at public healthcare centers they are registered by staff who collect their most important data and record it on either printed or electronic forms. Personal data, contact information, admission date and time, reason for admission, referring physician, public health identification number, etc. are recorded at this stage. At the same time at least one additional identification number is assigned to the admitted patient, which is also used in the patient's medical record. This number, along with other basic personal information, is either directly printed on the wrist bracelet that is usually generated and fitted to the patient, or printed on a label which is attached to it.

Later, the treating physician, with the assistance of other health care personnel, is 


\section{A Review of Automatic Patient Identification Options for Public Health Care Centers with Restricted Budgets}

responsible for filling out the patient's medical history in accordance with the particular model used in the public health system or the particular health care center [1]. Subsequent patient identification is still today generally performed manually by human observers in many public health care centers. Such human interaction in the course of patient identification is highly undesirable because it is inevitably prone to human error. The ensuing identification errors frequently result in serious mistakes when carrying out vital activities such as medication, blood transfusions, clinical trials, surgery, and a variety of other medical procedures.

The use of automated patient identification systems for patient identification is a practical means to reduce these risks [2]. Such systems can provide quick and reliable patient identification as well as remote instant access and management of patient medical history (EHR: "Electronic Health Record"). Although the main purpose of any system for this purpose is to improve the reliability of patient identification, providing a speedy access to clinical information is also a desirable feature. Additionally, the system must also include aspects of security and confidentiality of the medical data to be handled.

Several research groups, as well as commercial health technology solutions providers, have been developing automated patient identification systems. Two main technologies are generally used: Graphic one-dimensional (1D) codes, normally known as bar codes, which are printed on labels, and radio frequency tags (RFID, "Radio Frequency Identification"). These two technologies are today the most widely used by health care centers where automated ID systems are in place [3], [4]. Other technologies have begun to emerge recently. Most are based on the evolution of the traditional bar code into two-dimensional (2D) graphic codes [5]. These new 2D codes are a notable improvement with respect to bar codes, because they are as easily generated and printed as 1D code, but allow storing greater amounts information [6], [7]. They additionally incorporate other desirable features such as error correction.

The present assessment of available technologies was undertaken in the context of its possible deployment by a municipal public health agency that operates a network of local clinics. One of the most important aspects to be considered in deciding what system can be used for automatic identification and access to patient data is the issue of the tag reading device to be used by the health care center's personnel. Whereas health care centers with abundant budgets may opt for providing their staff with dedicated ID tag readers, many public health care facilities, especially in developing countries, cannot generally afford the purchase of such dedicated equipment, at least in sufficient numbers [8]. A very effective alternative to the dedicated ID tag reader for scarcely budgeted public health care centers is offered by the ubiquitous mobile smart phone. These devices could be provided by the center to its personnel for this purpose, or alternatively the hospital personnel may prefer to use their own devices. Of course, in this case the willingness of the personnel to do so must be fully ascertained.

The following sections describe the most relevant technologies available today to implement systems for automatic patient identification and access to patient data using the smart phone as an ID tag reader. Specifically, we consider graphic 1D codes (bar codes), various types of 2D codes, and active and passive RFID technologies. Their characteristics, 
advantages, disadvantages, and some background on selected pertinent applications are analyzed and compared. Attention is drawn to those features that would be most important in guiding the selection of a particular technology. The overall determining factor being the suitability of the system to cost-effectively accomplish the specific task of performing positive patient identification (PPI) and remote access to their EHRs by medical personnel within a public health care center environment.

\section{One-Dimensional Graphic Codes}

This vintage form of graphical encoding uses a combination of black and white parallel and adjacent areas of different thicknesses to represent information. Its design allows it to be automatically decoded by special reading devices. Usually these codes are not descriptive, but store a reference code associated with a database containing relevant information. These codes, sometimes also called "UPC Symbols" [6] were originally developed by IBM and used for the first time in 1967 [9].

As shown in Figure 1, which schematically presents the general structure, the code begins with a "start character" and ends with an "end character," that identify the beginning and end of information. The actual data is contained between these two starting and ending characters. Two "quiet zones," at least $1 / 4$ inch long, are placed before and after the start and end characters, respectively, for ease of reading. In some types of 1D codes a control digit, or "checksum," is included to add security to the data contained in the code, as it ensures that the reading's decoding is correct. This check digit is obtained by performing logicalmathematical operations on the other characters of the code.

\section{Illustrative examples of $1 \mathrm{D}$ code use in health care}

There are numerous precedents of this technology's use in health care centers. Most of them are based on bar codes to control the hospitalized patient's medication process, blood transfusions, and in laboratory tests (blood, urine, etc.) to identify the test/patient pair. Two examples illustrative of ID code usage in patient identification are listed below:

- Houston's "Methodist Hospital System," one of the largest in the state of Texas (USA), uses a patient data electronic verification system, designated KBMA, based on the reading of bar codes. It is connected online to the medical documentation system "MethOD" (medical records database) [10].

- The Joint Commission on Accreditation of Healthcare Organizations (JCAHO) has been proposing since 2007, along with its hospital accreditation program, a patient safety plan using bar codes. The JCAHO plan expects hospitals to instrument systems requiring that each patient wear a bracelet with a printed barcode that must be scanned to verify the correct patient identity before administering any medications or blood transfusions [11]. 


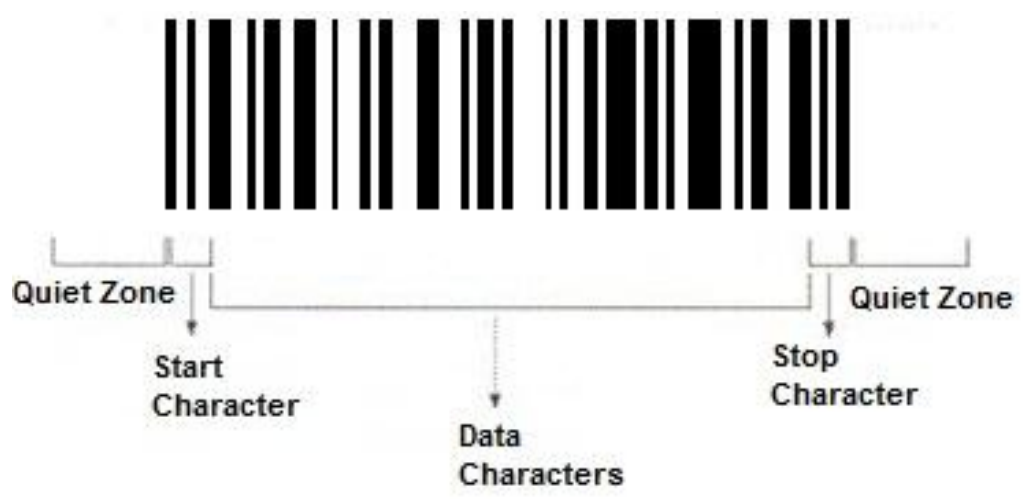

Figure 1. General structure of 1D codes.

\section{Types of 1D code}

There are various types of 1-D bar codes, whose characteristics may not always differentiate them from each other. Most of them were originally developed to meet the needs of specific industries and were then standardized for use in different areas. Among the most relevant types available are: UPC (Universal Product Code), EAN (European Article Numbering), Code 39, Code 128, and the Interleaved 2 of 5.

\section{Some characteristics of $1 \mathrm{D}$ code}

The main advantages of 1-D technology can be summarized as follows:

- Fast data capture.

- Reliability due to the very low level of errors in the capture and decoding of data.

- Immediate integration of the decoded data into the system or database.

- Low cost of printing the codes.

Their main disadvantage compared to other alternatives such as 2D codes and RFID is that they have a relatively low storage capacity of approximately 20 to 30 digits.

\section{Typical current applications of $1 \mathrm{D}$ code}

One-dimensional codes were used initially in commercial environments for product identification. At present the use of automated identification 1D codes has spread extensively to many other areas such as manufacturing, consumer trade, mail, transport, the health sector, and so on. Some examples of specific applications are:

- Inventory control.

- Tracking of moving objects such as cars, baggage, mail, packages, medicines, laboratory test samples, etc.

- Access control to transportation, open-air events, buildings, offices, theaters, etc.

- $\quad$ PPI in Hospitals.

\section{Two-Dimensional Graphic Codes}

Two-dimensional codes are in general capable of storing alphanumeric characters including 
letters, numbers and punctuation. Non- alphanumeric characters, such as Kanji, can also be stored [6], [9]. The way to store information is to represent it two-dimensionally by means of planar distributed graphic patterns (dots, squares, circles, triangles, hexagons, etc.). The two-dimensionality of these codes allows a greater data storage density than is possible with traditional 1-D bar codes. Thanks to this feature, 2D codes use about a tenth of the area required by a 1-D code to store a similar amount of data. Figure 2 shows how graphic codes have evolved from the original bar codes to the development of 2-D codes in the 90's.

The recent use of 2D code technology for patient identification applications within the hospital environment provides a significant improvement of all health care related identification applications [12]. The implementation of this technology allows to quickly and effectively verify a patient's identity and data before administering medications, performing medical procedures, and even permits to monitor patients' location and movement to different hospital areas or other centers within the public health care system.

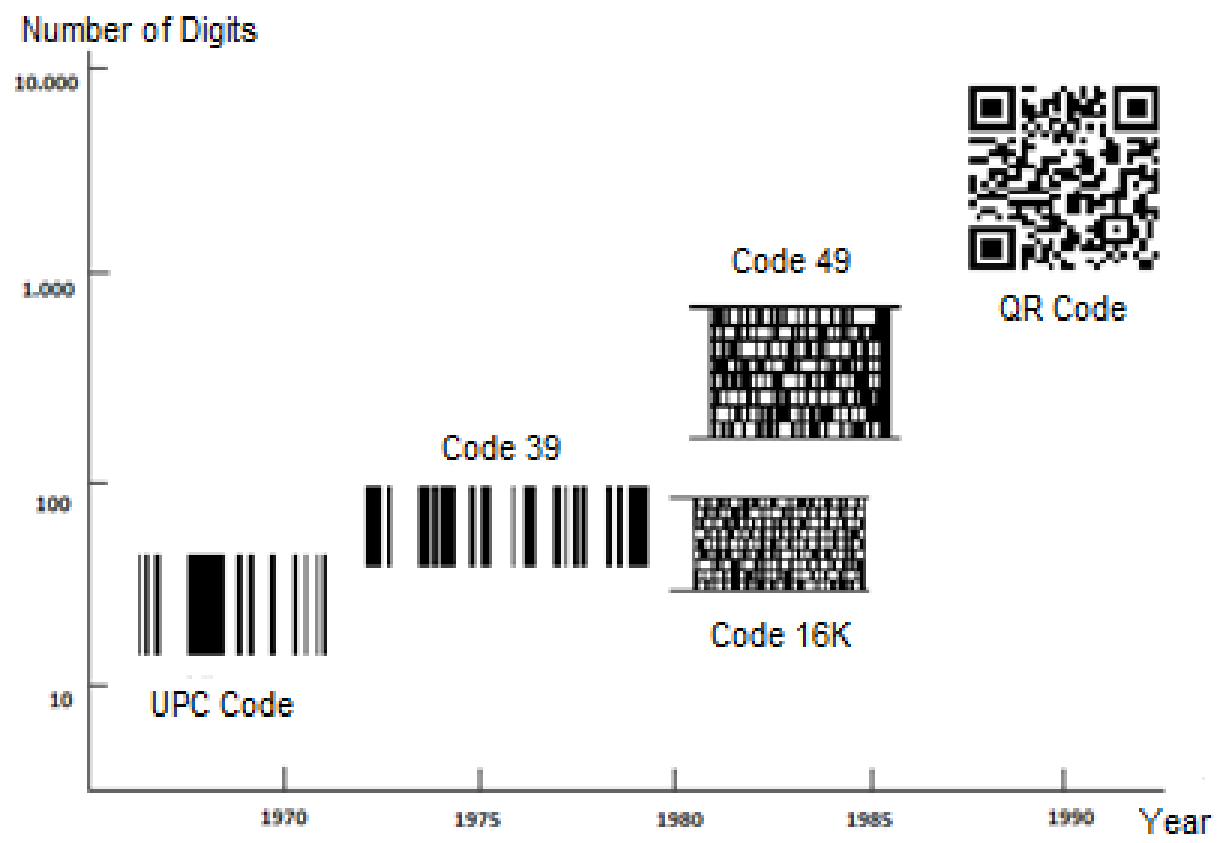

Figure 2. Historic evolution of graphic codes [6].

The most significant types of 2D code are: Code 49, PDF417, and 2D Matrix [9]. The Matrix code may be divided into several sub-types, including: Data Matrix [13], Semacode [14], MaxiCode [15], HCCB [16], QR code [17], SPARQCode [18], among others. Table 1 presents a comparison of some characteristics of three of the major 2D code types available today. 
A Review of Automatic Patient Identification Options for Public Health Care Centers with Restricted Budgets

Table 1. Comparison of relevant characteristics of three 2D code types [9]

\begin{tabular}{|c|c|c|c|c|}
\hline \multicolumn{2}{|l|}{ Name: } & PDF417 & Data Matrix & QR Code \\
\hline \multicolumn{2}{|c|}{ Appearance: } & (1) & $\begin{array}{l}\text { Pyz } \\
\text { ming }\end{array}$ & 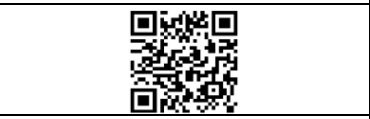 \\
\hline \multicolumn{2}{|l|}{ Source: } & $\begin{array}{l}\text { Symbol Technol. } \\
\text { (USA) }\end{array}$ & $\begin{array}{c}\text { RVSI Acuity } \\
\text { CiMatrix (USA) }\end{array}$ & DENSO (Japan) \\
\hline \multicolumn{2}{|l|}{ Type: } & Stacked 1D Bars & 2D Matrix & 2D Matrix \\
\hline \multirow{4}{*}{$\begin{array}{l}\text { Storage } \\
\text { Capacity }\end{array}$} & Numer. & 2710 & 3116 & 7089 \\
\hline & $\alpha$-num. & 1850 & 2355 & 4296 \\
\hline & Binary & 1018 & 1556 & 2953 \\
\hline & Kanji & 554 & 778 & 1817 \\
\hline \multicolumn{2}{|c|}{ Advantages } & $\begin{array}{c}\text { Higher capacity than } \\
\text { Bar Code. }\end{array}$ & $\begin{array}{l}\text { High capacity, } \\
\text { Small size. }\end{array}$ & $\begin{array}{l}\text { High capacity, Small } \\
\text { size, High scanning } \\
\text { speed, } \\
\text { Error correction. }\end{array}$ \\
\hline
\end{tabular}

\section{Illustrative examples of $2 \mathrm{D}$ code use in health care}

There are several instances of the use of this technology in medical settings, some of which are outlined below:

- Some medical institutions, mainly in the Asia-Pacific region, have adopted this technology for patient identification, and access and control of patient data. Health care centers in Japan and Singapore [6], and more recently in Hong Kong, have implemented a system known as UPI (Unique Patient Identification), which in 2008 achieved full technology transition from 1D to 2D codes [7].

- Addenbrooke's Hospital in Cambridge uses 2D codes as part of its patient safety policy [12]. A bracelet on which a 2D code is printed, in addition to other basic personal data, is attached on each patients' wrist. At first the system was used only to track blood transfusions and to check coincidence between patient and blood type. Currently the use of 2D codes has been extended to other areas to reduce the occurrence of some other types of medical errors [12].

- $\quad$ An update of Houston's Methodist Hospital KBMA 1D code-based ID system has been proposed, consisting of migrating its old $1 \mathrm{D}$ code-based patient identification to a $2 \mathrm{D}$ code-based system [10].

\section{Some relevant characteristics of $2 \mathrm{D}$ code}

Two-dimensional code requires a more complex processing and a longer processing time to decode the data than its predecessor the 1D code [6]. This complexity is due to its larger capacity to store information. The required more complex processing calls for more 
sophisticated, and therefore more expensive, reading devices. However, the significance of the problem has been declining lately because of the considerable progress recently made by image recognition and processing technology [9].

The impact of the cost factor has been further reduced nowadays because of the increasing multimedia capabilities that are being incorporated into modern camera-equipped mobile smart phones and PDAs, Such processing capabilities enable these relatively inexpensive devices to replace the otherwise costly dedicated 2D code readers/decoders [19].

There are currently available a variety of special programs for this purpose that run in camera-equipped mobile smart phones [20]. These programs can decode the information stored in the 2D codes printed on the patient's bracelet, display it on the phone's screen, and even activate other functions, such as dialing a telephone number, or using the smart phone's Internet connection to send email and to remotely link to EHR (Electronic Health Records) data bases to retrieve, or input, patient's specific medical information.

The main advantage of the use of $2 \mathrm{D}$ codes for patient identification over other more complex types of identification comes from its simpler technology. 2D code-based technology is much more accessible to users mainly because it does not require the use of any special tags (such as the RF tags discussed in the next section). Instead, 2D codes can be very easily generated and printed on a variety of paper or plastic labels, or on any other surface, without the use of specialized equipment.

Reading and decoding 2D codes, especially with a smart phone, is likewise technologically simpler than other more complex technology-based systems. Additionally, in general the camera-based optical capture of 2D code-based readers, including smart phones, inherently has a much narrower capture field than radio frequency-based reading devices. Thus, they are less prone to erroneous positive identification, since it is practically impossible for these readers to mistakenly acquire signals from unintended nearby sources. In this respect, 2D code reading is unambiguous since it requires close proximity of the reader device to the patient's bracelet to capture the code.

\section{Typical general applications of $2 \mathrm{D}$ code}

Nowadays 2D codes are increasingly showing up in a variety of application areas, such as for example:

- Boarding passes in transportation.

- Advertising in newspapers, magazines, posters and billboards.

- Inventory management.

- $\quad$ Tickets for public events.

- Personal contact cards.

- Health services.

The use of 2D codes is also gradually growing within the hospital environment, typically in patients' bracelets, medical equipment, laboratory samples and drugs, administration of medicines, medical procedures, and tracking of internal and external transfer of patients [12]. 


\section{Radio Frequency Identifiers}

Radio Frequency Identification (RFID) technology can automatically identify people and objects in the healthcare environment by placing identifier RFID tags on the subjects and then remotely reading them using a specialized reader devices [21]. This technology has already been used for a variety of healthcare applications, such as hospital assets, staff, and patient tracking; positive patient identification (PPI); biosensing; medical procedures alerts; medication control; etc. [22], [23], [24]. The system typically consists of four elements: a label (tag) located on the subject to be identified (patient, medication, lab sample, etc.); the reader or coupler device that reads or writes information on the label; the transmitting antenna; and the database or computer system that handles and processes the information captured from the labels. Each tag contains a unique identification number (UIN) which is transmitted to the reader whenever required [25]. Apart from its identification purpose, the UIN may also serve as a reference command to interface with a database that containing additional information. In addition to reading the information stored in an RFID tag, the reader device, if necessary, may be able to write into the tag's memory.

\section{Some applications of RFID}

The most significant applications were RFID technology is currently used are:

- Access control.

- Inventory Management.

- Baggage identification and screening.

- Industrial production chains.

- Library book input and output.

- Identification and location of animals.

- Healthcare.

\section{Illustrative examples of RFID use in health care}

There are a growing number of proposals and projects that are being considered or are currently being implemented in health care centers for the use of automated identification, access, management and control of patient data based on RFID technology. Below are three representative examples:

- Taichung Hospital in Taiwan implemented an RFID-based system, integrated with the Hospital Information System (HIS), to improve the efficiency of patient safety during the medication process of hospitalized patients [21].

- The Orthopaedic Institute of Palm Beach, Florida, put into operation a system known as "SurgiChip" that uses RFID patient identification to help prevent surgical errors [21]. At the time of admission a smart tag is generated containing patient data, place of surgery and specific surgical information and instructions. The RFID tag is read by a dedicated scanner and placed before surgery at the location on the patient's body where the surgical procedure is to be performed. The information obtained from the label is communicated to and corroborated by the patient before being sedated. Later the tag is read again in the operating room and the surgeon verifies that the information corresponds to the ID number and to the clinical data printed on the patient's bracelet. Only when all the information matches the surgeon proceeds to perform the surgical procedure [26]. 
- A system for patient identification using a bracelet with a customized RFID tag was proposed by O'Halloran and Glavin [27]. Unlike other RFID systems, which store data in the tag itself, RFID tags are used in this case only as a means to identify the patient and to gain access to the patient's HER which is stored in a centralized database. HERs containing medical data, including medical images, may be modified only by authorized medical staff.

\section{Types of RFID tags}

Labels or "tags" may be classified in various ways. One classification of RFID tags functionally separates them into six classes according to their ability to read and write stored data. This scheme was proposed by EPCglobals, an organization that develops standards for EPC use (Electronic Product Code) in RFID networks [25].

In general RFID tags can be divided into three main classes: active, passive, and semipassive. Passive tags must receive their operating energy from the reader device. To that end, the reading device's emitted RF electromagnetic field, when placed in close proximity to the RFID tag, is coupled to the tag's antenna. The RFID tag then rectifies the received RF signal and harvests the energy necessary for its operation. On the other hand, active RF tags can initiate communications with the reader device by themselves, because they contain their own internal energy sources.

Passive tags are used for patient identification, real-time location service of medical assets, and drug inventory control and monitoring [28]. They are most adequate RFID type for placing on patients' bracelets in patient identification applications.

\section{Operating frequencies}

The operating frequency defines the speed of data transfer. The lower the frequency is, the shorter the data transfer rate [21]. The range is also affected by the operating frequency. Maximum reading range has important consequences for RFID-based PPI applications. A large capture range facilitates the unintentional acquisition of signals originating from nearby sources other than the subject's bracelet, leading to possible failed or incorrect identification. RFID tags typically operate at frequencies within one of three bands: one at low frequencies up to $135 \mathrm{kHz}$, and two around $13.56 \mathrm{MHz}$ and $2.45 \mathrm{GHz}$ [21]. However recently there is an increasing interest in using $900 \mathrm{MHz}$ for these applications. Passive tags commonly operate at frequencies such as $128 \mathrm{kHz}, 13.6 \mathrm{MHz}, 915 \mathrm{MHz}$ and $2.5 \mathrm{GHz}[1]$. Active RFID tags, on the other hand, usually operate at high frequencies, depending on the distance and memory requirements of the application for which they are used.

\section{Some relevant characteristics of RFID}

This technology presents certain advantages compared to other alternatives. RFID tags can store an amount of information in general larger than any graphic code, and considerable more when compared to traditional 1D code (bar codes). Furthermore, it does not require the existence of a short line of sight link between the tag and the reader, as graphic codes require. Therefore information can be generally accessed at distances up to about 9 meters 
or more, depending on the configuration and operating frequency [25]. However for many applications, including patient identification, this apparent advantage is rather a disadvantage, because of the inherent reduced target selectivity, as compared to the highly selective short line-of-sight distances used for graphic code capture.

Perhaps the single main disadvantage, with respect to graphic code technology, that persists today for the use of RFID technology in patient identification applications is its relatively higher cost, both of the reading devices and, especially, of the labels. Additionally the need for batteries represents an issue for active RFID tags. Another important disadvantage is the greater complexity of implementing and operating RFID technology [22].

\section{Near Field Communications tags}

An emerging technology closely related to RFID is Near Field Communication (NFC). NFC is a wireless connectivity technology that uses magnetic field induction to establish a communication link between electronic devices placed in close proximity to each other [29]. The use of NFC tags in conjunction with NFC-enabled mobile phones could be an attractive technology for unambiguous and secure automatic patient identification [30]. Although still incipient in its use and not sufficiently proven in patient identification applications, this technology may soon show its potential in avoiding some of the inherent shortcomings that standard RFID technology has for this purpose.

\section{Suitability of the Available Technologies}

Table 2 provides an organized general comparison between the three main available technologies that can be used readily today for automatic patient identification and access to patient data purposes [9], [17], [21], [25], [31].

A major cause for concern regarding the use of RFID technology use in the healthcare environment is its associated positional uncertainties [32][LA10]. RFID technology's inherent longer range, excluding NFC, is prone to identification ambiguity, which is naturally avoided by graphic code technology that requires close proximity between the tag and the reader device.

Table 2. Comparison of three major technologies suitable for automatic patient identification

\begin{tabular}{|c|c|c|c|}
\hline \multicolumn{1}{|c|}{ Features } & 1D Codes & 2D Codes & RFID \\
\hline Encoding Method: & $\begin{array}{c}\text { Printed variable- } \\
\text { width parallel bars. }\end{array}$ & $\begin{array}{c}\text { Printed two- } \\
\text { dimensional } \\
\text { geometric patterns. }\end{array}$ & $\begin{array}{c}\text { Radio Frequency } \\
\text { tag. }\end{array}$ \\
\hline Type of decoder: & $\begin{array}{c}\text { Dedicated optical } \\
\text { scanner. }\end{array}$ & $\begin{array}{c}\text { Camera- equipped } \\
\text { smart phone or PDA, } \\
\text { dedicated scanner. }\end{array}$ & $\begin{array}{c}\text { Special dedicated } \\
\text { RF reader device. }\end{array}$ \\
\hline & & Descriptive (general & Unique \\
\hline
\end{tabular}


A Review of Automatic Patient Identification Options for Public Health Care Centers with Restricted Budgets

\begin{tabular}{|c|c|c|c|}
\hline Stored data: & Reference number. & $\begin{array}{l}\text { data, web links, } \\
\text { contact, etc.) }\end{array}$ & $\begin{array}{l}\text { identification } \\
\text { number (UIN) }\end{array}$ \\
\hline Type of data: & $\begin{array}{l}\text { Numeric, } \\
\text { alphanumeric, } \\
\text { ASCII, control }\end{array}$ & $\begin{array}{c}\text { Numeric, } \\
\text { alphanumeric, } \\
\text { binary, Kanji. }\end{array}$ & $\begin{array}{l}\text { Numeric, } \\
\text { alphanumeric, } \\
\text { binary. }\end{array}$ \\
\hline $\begin{array}{l}\text { Data Security / Error } \\
\text { Correction Method: }\end{array}$ & $\begin{array}{l}\text { Although optional } \\
\text { in some types, most } \\
\text { use Checksum. }\end{array}$ & $\begin{array}{l}\text { Reed-Solomon } \\
\text { coding: adds } \\
\text { redundancy. } \\
\text { Partially corrupted } \\
\text { code can be read. }\end{array}$ & $\begin{array}{l}\text { No inherent error } \\
\text { correction, but } \\
\text { frequently include } \\
\text { error correction } \\
\text { codes }\end{array}$ \\
\hline $\begin{array}{l}\text { Capacity } \\
\text { (characters): }\end{array}$ & Up to 30 & $\begin{array}{c}\text { Numeric: } \\
138 \text { to } 7089 \\
\text { Alphanumeric: } 93 \text { to } \\
4296 \\
\text { Binary: } \\
1556 \text { to } 2953 \\
\text { Kanji: } \\
778 \text { to } 1817 .\end{array}$ & $\begin{array}{l}\text { From } 512 \text { bits to } \\
512 \text { kBytes. Active } \\
\text { tags have greater } \\
\text { capacity than } \\
\text { passive ones. }\end{array}$ \\
\hline Advantages: & $\begin{array}{l}\text { - High speed data } \\
\text { capture. } \\
\text { - Reliability. } \\
\text { - Integration with } \\
\text { database. } \\
\text { - Easily printed } \\
\text { low-cost labels. }\end{array}$ & $\begin{array}{l}\text { - Short range*. } \\
\text { - High storage } \\
\text { capacity, small size. } \\
\text { - Stores diverse } \\
\text { kinds of data. } \\
\text { - Easily printed low- } \\
\text { cost labels. } \\
\text { - Inherent error } \\
\text { correction. } \\
\text { - Smart phone } \\
\text { readable. }\end{array}$ & $\begin{array}{l}\text { - High-storage } \\
\text { capacity. } \\
\text { - Read and write } \\
\text { allowed. } \\
\text { - Can be } \\
\text { automatically } \\
\text { scanned. } \\
\text { - Can act as } \\
\text { biosensor. }\end{array}$ \\
\hline Disadvantages: & $\begin{array}{l}\text { - Low-storage } \\
\text { capacity. } \\
\text { - Limitations on the } \\
\text { types of data they } \\
\text { can store. }\end{array}$ & $\begin{array}{l}\text { - Must be manually } \\
\text { scanned. }\end{array}$ & $\begin{array}{l}\text { - Long range*. } \\
\text { - Complex use and } \\
\text { set up. } \\
\text {-needs special tags } \\
\text { and dedicated } \\
\text { readers. } \\
\text {-Security issues. }\end{array}$ \\
\hline
\end{tabular}

${ }^{(*)}$ Referred to unambiguous patient ID applications.

Another limitation of RFID technology is its effect on the healthcare environment. Whereas graphic code technology is totally innocuous to it, RFID technology, on the contrary, poses non trivial risks regarding its potential electromagnetic interference with the other medical devices in the health care center [33].

Finally, the issue of the availability and cost of the reading device must be given serious 
attention, especially when the patient identification technology is to be set up in a low budget public health care center, as would probably be the case in developing countries. In this respect, the possibility of using mobile smart phones as the reading devices represents a very strong asset to consider when making a technology choice decision.

A full installation and operation cost analysis and evaluation, which should precede the adoption of any particular patient identification technology, is not included in the present brief survey. However, the features, advantages, disadvantages and other peculiarities of the available technologies that have been described here clearly point towards $2 \mathrm{D}$ graphic tag technology as the least complex and most cost-effective choice (see Table 3).

\section{Discussion}

Among the several 2D code options for patient identification, QR code technology emerges as the attractive alternative. QR code-based applications intended for the healthcare sector are constantly increasing. The distinct characteristics of QR code-based technology, such as high data storage capacity, low implementation cost, technical simplicity, widespread use, and the ample availability of free programs for reading and decoding it by camera-equipped smart phones, makes this technology outstandingly attractive for unambiguous patient identification, especially for low budget applications and in developing countries in particular.

QR Code (see Figure 3) is one of the latest 2D codes to be developed. It presents several advantages compared to other 2D codes since its characteristics surpass those of the other types [6]: a higher data capacity, printing in smaller areas or sizes, and fast reading.

Two of the most distinctive characteristics of QR code [17] are summarized below:

- An error correction ability to recover up to 30\% of the "codeword" ( 1 codeword = 8 bits).

- A capacity to be read or tracked in any direction, and to tolerate bending distortion. This is because the code contains position detection patterns in three of the corners (see Figure 3). This allows the reader device to know the code's position and correctly decode it, without any reader device misalignment affecting the reading speed.

Table 3. Cost comparison of $2 \mathrm{D}$ and RFID technologies

\begin{tabular}{|c|c|c|}
\hline & 2D Codes & RFID \\
\hline Labels / Tags & Optional & $\$ 10 / 100-400$ \\
\hline Reading Device & $\$ 150-400$ & $\$ 1500-3000$ \\
\hline Printer & Optional & $\$ 3000$ (smart labels) \\
\hline
\end{tabular}



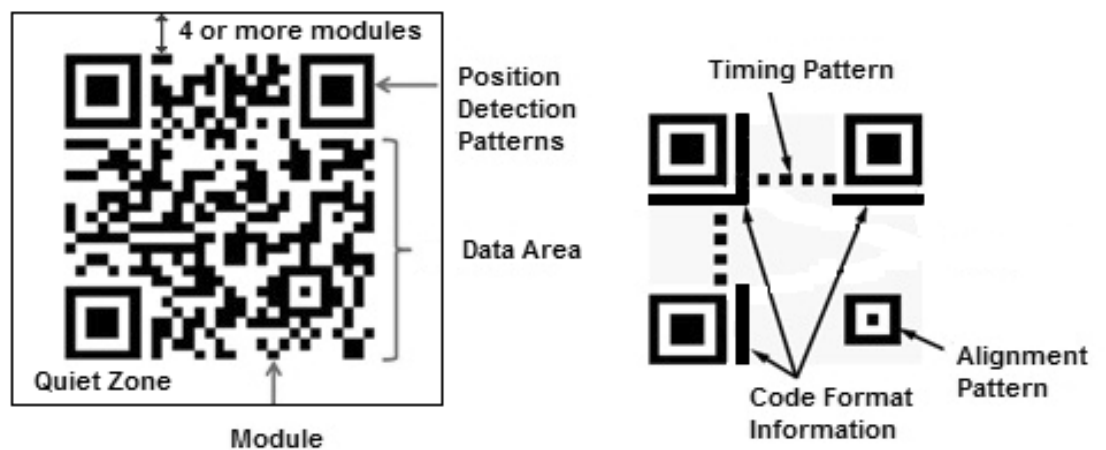

Figure 3. QR Code characteristic patterns

\section{Conclusion}

Decreasing medication errors, improving patient safety and increasing the accuracy of clinical procedures are important contributing factors to reduce public health care costs and enhance the quality of public health care. The use of automatic patient identification systems positively impacts these factors and significantly improves the access to and delivery of public health care services.

We have presented an assessment of automatic tag reading technologies that are presently suitable for patient identification purposes. Special attention was given to cost-effectiveness and technology availability in a framework of public health care centers with restricted budgets. In this context, mobile smart phones are recognized as the best choice for reader devices, considering their ubiquity and widespread use. The smart phone has the advantage over other reading devices of additionally acting as a network terminal through which the patients' EHRs, and other pertinent medical information, may be remotely and interactively accessed by the health care center's authorized personnel.

The main conclusion of this comparative assessment is that the use of $2 \mathrm{D}$ codes, and QR codes in particular, presently embodies the best choice for setting up automatic patient identification capabilities in low-budget public health care centers. The use of QR codebased tag technology, when combined with mobile smart phones as code reading and decoding devices, seems to be the most practical and cost-effective alternative available today for automatic patient identification, as well as for quick remote health record access, by medical personnel in public health care systems with limited budgets.

The present assessment did not focus on the issue of mobile smart phone usage as reading devices in the clinical environment. However, this is an important aspect that needs to be addressed. The capacity of the public health system administration to supply mobile smart phones to its medical personnel for patient identification purposes, or alternatively, their willingness to use their personal devices, must be carefully ascertained before making a decision. 


\section{Acknowledgements}

This work was funded by the Office of the Dean of Research, Simón Bolívar University Caracas, Venezuela.

\section{Corresponding Author}

Rebeca I. García-Betances

Networks and Applied Telematics Group (GRETA)

Simón Bolívar University

Apdo Postal 89000

Caracas 1080, Venezuela

E-mail: rebecaisabel@gmail.com

\section{References}

[1] Cangialosi A, Monaly J, Leveraging RFID in Hospitals: Patient Life Cycle and Mobility Perspectives. IEEE Communications Magazine, 2007;45(9):18-23.

[2] Frisch P, Miodownik S, Booth P, Carragee P, Dowlin M, Patient Centric Identification and Association, Proc of 31st Annual Int. Conf. IEEE Engineering in Medicine and Biology Society (EMBS), 2009:1722-1725.

[3] Booth P, Frisch PH, Miodownik S, Application of RFID in an Integrated Healthcare Environment, Proc. of 28th Annual Int. Conf. IEEE Engineering in Medicine and Biology Society (EMBS), 2006:117-119.

[4] Chowdhury B, Khosla R, RFID-based Hospital Real-time Patient Management System," 6th IEEE/ACIS Int. Conf. on Computer and Information Science (ICIS), 2007:363-368.

[5] Ebling E, Cáceres R, Bar Codes Everywhere You Look, IEEE Pervasive Computing, 2010;9(2):4-5.

[6] Tan Jin Soon. QR Code. Synthesis Journal, 2008, section 3, Available on-line at: http://www.itsc.org.sg/pdf/synthesis08/Three_QR_Code.pdf. Accessed January 2012.

[7] HA Quality \& Risk Management Annual Report. Patient Safety and Risk Management Department, Hong Kong Hospital Authority, 2010, Available on-line at: http://www.ha.org.hk/haho/ho/psrm/EngCopyQRMReport.pdf. Accessed January 2012

[8] Zalzala A, Chia S, Zalzala L, Karimi A, Healthcare technologies in developing countries, IEEE GCC Conf. and Exhibition, 2011:629-632.

[9] Yeh Y-L, You J-C, Jong G-J, 2D Bar-Code Technology Applications in Medical Information Management. 8th Int. Conf. on Intelligent Systems Design and Applications, 2008:484-487.

[10] The Methodist Hospital System: Upgrade to bar code identification of patients yields significant process and safety gains. ID Solutions for Healthcare, General Data Company, 2008, Available on-line at: www.general-data.com/healthcare. Accessed January 2012.

[11]Bar Code Technology Saves Money and Lives in Health Care Applications: White Paper, Integrated Software Design, Inc. Available on-line at: www.isdweb.com. Accessed January 2012. 
[12] Positive Patient Identification Wristband Solutions, SATO Healthcare ID Solutions. Available on-line at: $\underline{w w w}$.satoeurope.com. Accessed January 2012.

[13] Data Matrix ECC200, TEC-IT Datenverarbeitung GmbH, Austria, Available on-line at: http://www.tec-it.com/en/support/knowbase/symbologies/datamatrix/Default.aspx.

Accessed January 2012.

[14] Semacode Corporation, Ontario, Canada. Available on-line at: http://semacode.com/. Accessed January 2012.

[15] ISO/IEC 16023:2000, MaxiCode International Symbology Specification, International Organization for Standardization. 18/04/2007.

[16] About High Capacity Color Barcode Technology, Microsoft Corporation 2011, Available on-line at: http://research.microsoft.com/en-us/projects/hccb/about.aspx. Accessed January 2012.

[17]QR Code, Denso Wave, Japan, Available on-line at: http://www.densowave.com/qrcode/qrstandard-e.html. Accessed January 2012.

[18] Spaqcode, MSKYNET, Inc. 2011, Available on-line at: http://www.sparqcode.com/static/tos. Accessed January 2012.

[19] Wakahara T, Yamamoto N, Image Processing of Dotted Picture in the QR Code of Cellular Phone, Int. Conf. on P2P, Parallel, Grid, Cloud and Internet Computing (3PGCIC), 2010:454-458.

[20]Liu Y, Yang B, Yang J. Bar Code Recognition in Complex Scenes by Camera Phones, 4h Int. Conf. on Natural Computation, 2008:462 - 466.

[21]Lai C-L, Chien S-W, Chang L-H., Chen S-C, Fang K. Enhancing Medication Safety and Healthcare for Inpatients Using RFID, PICMET 2007 Proceedings, Portland, Oregon, 2007:2783 - 2790.

[22] Yao W, Chu C-H, Li Z, The Use of RFID in Healthcare: Benefits and Barriers, Proc. IEEE Int. Conf. on RFID-Technol. and Appl., Guangzhou, China, 17-19 June 2010:128-134.

[23] Wamba SF, Ngai EWT, Unveiling the Potential of RFID-Enabled Intelligent Patient Management: Results of a Delphi Study, Proc. 44th Hawaii Int. Conf. on System Sciences, 2011:1-10.

[24] Venkatalakshmi B, Renold AP, Packiam RSL, Smart RFID Care [SRC] for Pervasive Health Care System, Proc. 3rd IEEE Int. Conf. on Comm. Software and Networks (ICCSN), 2011:650-653.

[25] Panescu D, Emerging Technologies: Healthcare applications of RF identification, IEEE Engineering in Medicine and Biology Magazine, 2006;25(3):77 - 83.

[26] Bacheldor B, InfoLogix Regenerates SurgiChip, Health Care News, RFID Journal, 2008. Available on-line at: www.rfidjournal.com. Accessed January 2012.

[27] O'Halloran M, Glavin M, RFID Patient Tagging and Database System, Proc. of Int. Conf. on Networking, Systems, Mobile Comm. and Learning Technologies (ICN/ICONS/MCL), 2006:162.

[28]Polycarpou AC, Gregoriou Papaloizou GL, Polycarpou P, Dimitriou A, Bletsas A, Sahalos JN, A healthcare application based on passive UHF RFID technology, Proc. 5th European Conf. on Antennas and Propagation (EUCAP), 2011:2814-2818.

[29] Near Field Communication (NFC) Technology and Measurements White Paper, Rohde \& Schwarz GmbH \& Co. KG, Munich, Germany, 1MA182_2e, Roland Minihold-032011. 
[30] Marcus A, Davidzony G, Law D, Verma N, Fletcher R, Khanz A, Sarmenta L, Using NFC-enabled Mobile Phones for Public Health in Developing Countries, First Int. Workshop on Near Field Comm., 2009:30-35.

[31] Specifications for Popular 2D Bar Codes, Adams Communications, 1995. Available on-line at: http://www.adams1.com/. Accessed December 2011.

[32] Laskowski M, Demianyk B, Friesen MR, McLeod RD, Uncertainties Inherent to RFID Tracking Systems in an Emergency Departmen, IEEE Workshop on Health Care Management (WHCM), 2010:1-6.

[33]Censi F, Calcagnini G, Mattei E, Triventi M, Bartolini P, RFID in Healthcare Environment: Electromagnetic Compatibility Regulatory Issues, 32nd Annual Int. Conf. IEEE Engineering in Medicine and Biology Society (EMBS), 2010:352-355. 